\title{
Isolation and characterization of Escherichia coli serotype 0157:H7 and other verotoxin-producing $E$. coli in healthy Indian cattle
}

\author{
Dasharath B. Shinde (D), Surbhi Singhvi(iD, Santosh S. Koratkar(i) and Sunil D. Saroj(D) \\ Symbiosis School of Biological Sciences, Symbiosis International (Deemed University), Pune, Maharashtra, India. \\ Corresponding author: Santosh S. Koratkar, e-mail: santosh.koratkar@gmail.com \\ Co-authors: DBS: dash101335@gmail.com, SS: singhvi.surbhi@yahoo.com, SDS: sunil.saroj@ssbs.edu.in \\ Received: 05-06-2020, Accepted: 22-09-2020, Published online: 29-10-2020
}

doi: www.doi.org/10.14202/vetworld.2020.2269-2274 How to cite this article: Shinde DB, Singhvi S, Koratkar SS, Saroj SD (2020) Isolation and characterization of Escherichia coli serotype 0157:H7 and other verotoxin-producing E. coli in healthy Indian cattle, Veterinary World, 13(10): 2269-2274.

\begin{abstract}
Background and Aim: Cattle are the main reservoir of Escherichia coli O157:H7 and other verotoxigenic E. coli (VTEC); therefore, there is an increased risk of infection to humans by either direct or indirect mode of transmissions. However, the prevalence of E. coli O157:H7 in the healthy cattle population of India is yet to be ascertained. This study aimed to screen the dairy cattle in and around Pune, Maharashtra, India, for verotoxin-producing E. coli O157:H7.

Materials and Methods: A total of 257 rectal swabs were collected from 15 different organized and unorganized dairy farms of Pune during the period, January-March 2015. The screening involved enrichment in EC broth followed by differential identification on MacConkey sorbitol agar. The presumptive positive isolates were further confirmed by multiplex polymerase chain reaction (PCR) using primers specific to $r f b E(\mathrm{O} 157)$, fliC (H7), VT1 (MK1), and VT2 (MK2). Vero-toxicity and antibiotic sensitivity were examined in PCR confirmed isolates.

Results: Out of the 257 samples analyzed, 1.9\% (2/105) were positive for O157:H7 and 39\% (41/105) were positive for VTEC. Two PCR confirmed positive O157:H7 strains and two randomly selected PCR-positive VT strains exhibited in vitro cytopathic effect on Vero cells on day-7 post-inoculation. Antibiotic sensitivity profiling of O157:H7 strains exhibited resistance against penicillin G, kanamycin, ampicillin, tetracycline, gentamycin, cefotaxime, streptomycin, and piperacillin.

Conclusion: These findings reveal the presence of pathogenic E. coli O157:H7 in the healthy cattle of Pune; in a situation, wherein regular surveillance for $\mathrm{O} 157: \mathrm{H7}$ is not a norm. Therefore, the findings presented herein warrant routine surveillance and public awareness to prevent the transfer of such pathogens and manage health risks to the public.
\end{abstract}

Keywords: cattle, Escherichia coli O157:H7, shiga toxin, vero cells, verotoxin.

\section{Introduction}

Verotoxin-producing Escherichia coli, also known as Shiga toxin-producing E. coli, is an important foodborne and zoonotic pathogen. It is associated with several human diseases which include hemorrhagic colitis, diarrhea, thrombotic thrombocytopenic purpura (TPP), and potentially fatal hemolytic uremic syndrome (HUS) [1,2]. The most predominant serotype of verotoxigenic $E$. coli (VTEC) is $E$. coli O157 infecting more than 73,000 people, causative of 61 deaths each year, and an average, 500 outbreaks in the United States alone $[3,4]$. In the United States from 2003 to 2012, E. coli 0157 was causative for 390 outbreaks, 4928 illnesses, 1272 hospitalizations, and 33 deaths [5]. In Canada, a systematic investigation of the outbreaks concluded that E. coli $\mathrm{O} 157: \mathrm{H} 7$ infections are common and linked to mechanically tenderized beef. The findings prompted amendments to the Canada Food and Drug Regulations about the

Copyright: Shinde, et al. Open Access. This article is distributed under the terms of the Creative Commons Attribution 4.0 International License (http://creativecommons.org/licenses/by/4.0/), which permits unrestricted use, distribution, and reproduction in any medium, provided you give appropriate credit to the original author(s) and the source, provide a link to the Creative Commons license, and indicate if changes were made. The Creative Commons Public Domain Dedication waiver (http://creativecommons.org/ publicdomain/zero/1.0/) applies to the data made available in this article, unless otherwise stated. requirement for mechanically tenderized beef to be labeled and provide safe cooking instructions to consumers [6].

Transmission of $E$. coli $\mathrm{O} 157$ takes place through the fecal-oral route in which contact with the animal and visit to the farm has a predominant role [7]. Cattle are considered as the principal reservoir of VTEC O157:H7; therefore, it functions as a potential source for transmission of VTEC O157:H7 to humans by direct or indirect route [8]. VTEC has been isolated from healthy intestines of sheep, deer, and buffalo; the distribution is not restricted to a particular geographical area, and among the isolates, serotype $\mathrm{O} 157: \mathrm{H} 7$ is mostly associated with severe human infections [9]. The virulence attributed to O157:H7 is due to the secretion of Shiga toxins (Stx), which inhibits protein synthesis of the host cells, ultimately leading to cell death. The Shiga toxin subtypes, Stx1, and Stx2, are involved in the signal transduction and secretion pathway $[7,10]$.

A limited number of investigations to determine the prevalence of O157:H7 in India have been conducted. In 2002, Khan et al. [11] investigated STEC in hospitalized diarrhea patients, healthy cattle, and beef samples from Calcutta. In 2006, Manna et al. [12] reported the occurrence of verotoxin-producing, antibiotic-resistant $E$. coli $\mathrm{O} 157$ in cattle population from 
West Bengal. Hazarika et al. [13] reported the prevalence of VTEC 0157:H7 in beef from Bareilly.

Regular surveillance for O157:H7 is not a practice in India. Additional information on the prevalence of $\mathrm{O} 157: \mathrm{H} 7$ in a healthy cattle population will assist public health authorities in device policies to curtail its spread and prevent related infections. The study aimed to understand the prevalence of verotoxin-producing E. coli O157:H7 from healthy cattle in Pune.

\section{Materials and Methods}

\section{Ethical approval and informed consent}

Ethical approval for such type of study is not required. However, cattle were handled carefully during rectal swab collection. Prior consent was taken from owner of the cattle farm. The privacy and confidentiality of personal information of participating farms and farm owners are not disclosed in the manuscript.

\section{Reagents and chemicals}

Chemicals, bacterial and cell culture media, antibiotics, and FBS used in the present study were procured from HiMedia Laboratories Pvt. Ltd., India. Polymerase chain reaction (PCR) primers were synthesized from BioResource Biotech Pvt. Ltd., India. Other PCR reagents such as dNTPs, Taq DNA polymerase, and PCR buffers were procured from Bangalore Genei, Bengaluru, India. The chemicals used were of the highest purity available.

\section{Sample collection}

Rectal swabs of cattle were collected from various organized and unorganized farms in and around Pune district during the period January-March 2015. Rectal swabs were collected from 15 different dairy cattle (cow/buffalo) using the method previously described by Bessalah et al. [14]. Drinking water samples from six different farms were also collected and tested for the presence of VTEC. Details of the sample collection are provided in Table-1.

\section{Enrichment and screening}

Rectal swabs were directly collected into $3 \mathrm{ml}$ EC Medium (HiMedia-M127) and kept on ice while transferring to the laboratory [12]. Samples were incubated overnight at $37^{\circ} \mathrm{C}$ without shaking and streaked on MacConkey sorbitol agar (HiMedia-M298) and incubated at $37^{\circ} \mathrm{C}$ overnight. E. coli isolates were differentiated based on the ability to ferment sorbitol. Five representative colonies were picked from each plate and further purified by three passages on SMAC agar. The isolates were subjected to Gram staining and IMViC (Indole, Methyl Red, Voges-Proskauer test, and Citrate utilization test) [15]. The presumptive positive $E$. coli were further confirmed by PCR.

\section{DNA extraction}

DNA was extracted using the boiling method as described by Bessalah et al.[14] and Blanco et al [16] with few modifications. Briefly, colonies from the
Table-1: Details of rectal swabs collection from different farms in and around Pune, India.

\begin{tabular}{|c|c|c|c|c|c|}
\hline \multirow[t]{2}{*}{ Farm } & \multicolumn{2}{|c|}{ Male } & \multicolumn{2}{|c|}{ Female } & \multirow[t]{2}{*}{ Total } \\
\hline & Adult & Calf & Adult & Calf & \\
\hline 1 & - & - & - & 20 & 20 \\
\hline 2 & - & - & 1 & 21 & 22 \\
\hline 3 & - & - & 5 & 3 & 8 \\
\hline 4 & - & 1 & 11 & 3 & 15 \\
\hline 5 & $1(\mathrm{~B})$ & 2 & 8 & 10 & 21 \\
\hline 6 & 1 & 8 & 3 & 8 & 20 \\
\hline 7 & $1(\mathrm{~B})$ & $4(B)$ & $8(\mathrm{~B})$ & $7(B)$ & 20 \\
\hline 8 & - & 2 & 8 & 10 & $21 *$ \\
\hline 9 & - & 4 & - & 15 & 19 \\
\hline 10 & 1 & - & 8 & 1 & $11 *$ \\
\hline 11 & 1 & - & $27,3(B)$ & 5,1 (B) & $38 *$ \\
\hline 12 & - & - & $7,1(B)$ & 3 & $12 *$ \\
\hline 13 & - & - & 8 & 1 & $10 *$ \\
\hline 14 & - & - & 8 & 2 & 10 \\
\hline 15 & - & - & 6 & 3 & $10 *$ \\
\hline
\end{tabular}

* Represents one additional drinking water sample collected from farm and B in brackets, that is, (B) represents the respective rectal swab collected from buffalo and rest of all are cow swabs

SMAC plate were suspended in $1 \mathrm{~mL}$ sterile deionized water and placed in a water bath at $100^{\circ} \mathrm{C}$ for $10 \mathrm{~min}$. The supernatant was used as template DNA.

\section{Oligonucleotide primers used in the study}

Primers specific to $\mathrm{O} 157, \mathrm{H} 7$, and $V T$ genes were used. The details are listed in Table-1 $[17,18]$.

\section{PCR}

PCR was performed as described earlier by Nagano et al., [19]. Briefly, a total of $20 \mu \mathrm{L}$ reaction mixture containing $1 \mathrm{~L}$ of template DNA, $5 \mu \mathrm{M}$ each primer, $2.5 \mathrm{mM}$ dNTPs, and $1 \mathrm{U}$ Taq DNA polymerase were used. The thermal cycling conditions are shown in Table-2 [18]. The amplified product was analyzed by electrophoresis on $1.5 \%$ agarose gel, stained with ethidium bromide (EtBr), and visualized under UV transillumination.

\section{Vero cell assay}

Vero cells were procured from National Center for Cell Sciences, Pune, grown and maintained in Minimal Essential Medium (MEM, AL047S) supplemented with $10 \%$ fetal bovine serum (FBS, RM9955) and $1 \%$ antibiotic (penicillin and streptomycin, A001) [20].

\section{Preparation of cell-free culture filtrates}

PCR-positive O157:H7 and other VTEC isolates were inoculated in nutrient broth and incubated at $37^{\circ} \mathrm{C}$ overnight with constant shaking. The supernatant obtained after centrifugation at 13,000 RPM for $15 \mathrm{~min}$ was filtered using $0.22 \mu \mathrm{m}$ syringe filters. The bacterial pellet obtained was resuspended in $1 \mathrm{~mL}$ PBS and sonicated to obtain cell lysate. The lysate was centrifuged to remove debris at $13,000 \mathrm{rpm}$ for $10 \mathrm{~min}$ at $4^{\circ} \mathrm{C}$. The cell lysate was filter sterilized using $0.22 \mu \mathrm{m}$ filters. Both the culture supernatants and cell lysates were used for the cytotoxicity assay $[11,21]$. 
Table-2: The PCR primers and thermal cycling conditions used for the amplification of verotoxin-producing genes in Escherichia coli [18].

\begin{tabular}{|c|c|c|c|c|c|}
\hline \multirow[t]{2}{*}{ Primers } & \multirow[t]{2}{*}{ Target gene } & \multirow[t]{2}{*}{ Amplicon (bp) } & \multicolumn{3}{|c|}{ PCR conditions } \\
\hline & & & Denaturing & Annealing & Extension \\
\hline $\begin{array}{l}\mathrm{H} 7-\mathrm{F} \\
\mathrm{H} 7-\mathrm{R}\end{array}$ & fliC gene of $\mathrm{H} 7$ & 560 & $90^{\circ} \mathrm{C} 2 \mathrm{~min}$ & $60^{\circ} \mathrm{C} 1 \mathrm{~min}$ & $72^{\circ} \mathrm{C} 90 \mathrm{~s}^{*}$ \\
\hline $\begin{array}{l}\text { O157-F } \\
\text { O157-R }\end{array}$ & $r f b E$ gene of 0157 & 678 & $90^{\circ} \mathrm{C} 2 \mathrm{~min}$ & $60^{\circ} \mathrm{C} 1 \mathrm{~min}$ & $72^{\circ} \mathrm{C} 90 \mathrm{~s}^{*}$ \\
\hline $\begin{array}{l}\text { MK-1 } \\
\text { MK-2 }\end{array}$ & $V T$ gene & 227 & $90^{\circ} \mathrm{C} 2 \mathrm{~min}$ & $60^{\circ} \mathrm{C} 1 \mathrm{~min}$ & $72^{\circ} \mathrm{C} 90 \mathrm{~s}^{*}$ \\
\hline
\end{tabular}

*Represents final extension of $10 \mathrm{~min}$ at $72^{\circ} \mathrm{C}$ after 35 PCR cycles. PCR=Polymerase chain reaction

\section{Cytotoxicity assay}

The cytotoxic effect of VTEC was examined on Vero cells in a 96-well plate. The cell-free culture filtrates $(20 \mu \mathrm{L}$ of supernatant $/ 100 \mu \mathrm{L}$ of cell lysate) were incubated with Vero cells in a $100 \mu \mathrm{L}$ MEM. The Vero cells were microscopically observed for 7 days, and cytopathic effects (CPE) were recorded [22,23].

\section{Antimicrobial susceptibility testing}

PCR-positive O157 and O157:H7 isolates were characterized for antibiotic susceptibility on MuellerHinton agar ( $\mathrm{MH}$ agar) plates by the disk diffusion method using 14 different antibiotic disks (penicillin G, kanamycin, piperacillin, amikacin, gentamycin, cefotaxime, streptomycin, chloramphenicol, tetracycline, cotrimoxazole, azithromycin, nalidixic acid, ampicillin, and nitrofurantoin) [24]. The results of disk diffusion were interpreted using the standard guidelines of the Clinical and Laboratory Standards Institute.

\section{Results}

A total of 257 rectal swabs of healthy dairy cattle (cow/buffalo) were collected from 15 different organized/unorganized farms in and around Pune, Maharashtra, during the period January-March 2015 (Table-1).

\section{Screening of 0157:H7 and VTEC}

The initial screening of rectal swabs for $E$. coli O157:H7 was performed on MacConkey Sorbitol Agar (SMAC). Out of 257 samples, 105 were positive for sorbitol non-fermenting $E$. coli. The sorbitol non-fermenting colonies were further subjected to biochemical tests. The presumptive positive isolates were further confirmed for $\mathrm{O} 157, \mathrm{H} 7$, and $V T$ genes using multiplex PCR. All the sorbitol non-fermenting isolates were positive for the indole test and methyl red test and negative for Voges-Proskauer. Isolates were further tested for growth characteristics on eosin methylene blue (EMB) agar. On EMB agar the colonies appeared dark centered with a green metallic sheen. E.coli produces dark centered colonies on EMB agar with metallic sheen due to lactose fermentation and acid production. All 105 isolates screened on SMAC were screened in a multiplex PCR for O157, H7, and $V T$ genes using specific primers, as mentioned in Table-2. The multiplex PCR using three sets of primers showed three distinct bands. Out of 257 samples tested, H7 was detected in 29/105 (27.61\%), O157 was detected in 2/105 (1.9\%), and $V T$ was detected in 41/105 (39.04\%) samples. PCR confirmed E. coli $\mathrm{O} 157: \mathrm{H} 7$ was detected in 1/108 adult cow and $1 / 14$ adult buffalo; whereas, none of the samples from cow and buffalo calves were tested positive. PCR confirmed $E$. coli $\mathrm{H} 7$ was detected in 22/225 cow and $7 / 26$ buffalo. PCR confirmed $E$. coli $V T$ was detected in 34/225 cow and 7/26 buffalo (Table-3).

\section{Vero cell assay}

The $V T$ and O157:H7-positive isolates were further examined for cytotoxicity using Vero cells. All samples showed a cytotoxic effect on Vero cells, which may be due to the presence of verotoxins. CPE was observed in Vero cells exposed to both the VTEC and $\mathrm{O} 157: \mathrm{H7}$ isolates on post-inoculation day-7.

\section{Antimicrobial susceptibility testing}

The antimicrobial susceptibility of isolates was examined by the disk diffusion method using 14 different antibiotics, as described in the methods section. It was observed that the O157-positive isolate was resistant to penicillin $\mathrm{G}$, piperacillin, tetracycline, cotrimoxazole, ampicillin, and nitrofurantoin; whereas, O157:H7 isolates exhibited resistance to penicillin $\mathrm{G}$, piperacillin, ampicillin, and nitrofurantoin (Table-4).

\section{Discussion}

VTEC has evolved from a clinically restricted strain to a global public health concern during the past few decades and has been prevalent in food products of more than 30 countries. VTEC is the causative of a spectrum of illness in humans, from asymptomatic infections to severe bloody diarrhea and, in some instances, may lead to life-threatening conditions. The information on the prevalence of VTEC strain in India is rare. However, O157:H7 is the most isolated strain among VTEC-related infections. In addition to $\mathrm{O} 157: \mathrm{H} 7$, several other serotypes of VTEC have been isolated from humans, food, and animal sources; however, they are not characterized in detail for their virulence attributes. E. coli O157:H7 is the most prevalent VTEC in foodborne outbreaks in North America, Europe, and Japan [25].

Cattle are the main reservoir of E. coli $\mathrm{O} 157$ and non-O157 VTEC; therefore, frequently observed 
Table-3: Polymerase chain reaction screening for three different verotoxin-producing genes (O157, H7, and VT) in Escherichia coli isolates from cattle and buffalo.

\begin{tabular}{|c|c|c|c|c|c|c|c|c|c|}
\hline \multirow[t]{3}{*}{ Gene names } & \multicolumn{4}{|c|}{ Cattle } & \multicolumn{4}{|c|}{ Buffalo } & \multirow{3}{*}{$\begin{array}{c}\text { Drinking water } \\
\text { samples (6) }\end{array}$} \\
\hline & \multicolumn{2}{|c|}{ Calf } & \multicolumn{2}{|c|}{ Adult } & \multicolumn{2}{|c|}{ Calf } & \multicolumn{2}{|c|}{ Adult } & \\
\hline & $\begin{array}{l}\text { Male } \\
(17)\end{array}$ & $\begin{array}{c}\text { Female } \\
(100)\end{array}$ & $\begin{array}{c}\text { Male } \\
\text { (3) }\end{array}$ & $\begin{array}{c}\text { Female } \\
(\mathbf{1 0 5})\end{array}$ & $\begin{array}{c}\text { Male } \\
(4)\end{array}$ & $\begin{array}{c}\text { Female } \\
(8)\end{array}$ & $\begin{array}{c}\text { Male } \\
(2)\end{array}$ & $\begin{array}{c}\text { Female } \\
(12)\end{array}$ & \\
\hline 0157 & 0 & 0 & 1 & 0 & 0 & 0 & 1 & 0 & 0 \\
\hline $\mathrm{H} 7$ & 4 & 6 & 0 & 12 & 0 & 2 & 0 & 5 & 0 \\
\hline VT & 4 & 12 & 2 & 16 & 0 & 2 & 1 & 4 & 0 \\
\hline
\end{tabular}

Table-4: Antibiotic susceptibility of E. coli 0157 and $0157: \mathrm{H} 7$ isolates.

\begin{tabular}{|c|c|c|c|}
\hline \multirow[t]{2}{*}{ S. No. } & \multirow[t]{2}{*}{ Antibiotics ( $\mu \mathrm{g} / \mathrm{disk})$} & \multicolumn{2}{|c|}{ Representative $E$. coli isolates } \\
\hline & & 0157 & 0157:H7 \\
\hline 1. & Penicillin G (30) & $\mathrm{R}$ & $\mathrm{R}$ \\
\hline 2. & Kanamycin (30) & $\mathrm{S}$ & $\mathrm{S}$ \\
\hline 3. & Piperacillin (100) & $\mathrm{R}$ & $\mathrm{R}$ \\
\hline 4. & Amikacin (30) & $\mathrm{S}$ & $\mathrm{S}$ \\
\hline 5. & Gentamycin (10) & $\mathrm{S}$ & $\mathrm{S}$ \\
\hline 6. & Cefotaxime (30) & $\mathrm{I}$ & I \\
\hline 7. & Streptomycin (10) & $\mathrm{S}$ & $\mathrm{S}$ \\
\hline 8. & Chloramphenicol (30) & $\mathrm{S}$ & $\mathrm{S}$ \\
\hline 9. & Tetracycline $(30)$ & $\mathrm{R}$ & $\mathrm{S}$ \\
\hline 10. & Cotrimoxazole (25) & $\mathrm{R}$ & $\mathrm{S}$ \\
\hline 11. & Azithromycin (15) & $\mathrm{S}$ & $\mathrm{S}$ \\
\hline 12. & Nalidixic acid (30) & $\mathrm{S}$ & $\mathrm{S}$ \\
\hline 13. & Ampicillin (10) & $\mathrm{R}$ & $\mathrm{R}$ \\
\hline 14. & Nitrofurantoin (300) & $\mathrm{R}$ & $\mathrm{R}$ \\
\hline
\end{tabular}

$\mathrm{S}=$ Sensitive, $\mathrm{I}=$ Intermediate, and $\mathrm{R}=$ Resistant as per the standard guidelines of the Clinical and Laboratory Standards Institute. E. coli=Escherichia coli

as a zoonotic agent in human infection. Domestic cattle farming is a widespread household practice in rural India; due to which individuals can establish close contact with the cattle during daily routines. Therefore, sizeable Indian population is subjected to a risk of contracting E. coli O157:H7. On the contrary, in India, VTEC infections are not a significant problem; maybe, due to the presence of acquired antibodies at an early age and the cooking practices followed. In India, the majority of the population do not consume beef for religious reasons; therefore, the possible mode of VTEC transmission is through direct and indirect contact of cattle waste with vegetables, fruits, and drinking water. E. coli $\mathrm{O} 157: \mathrm{H} 7$ has been isolated from a variety of food products marketed in India.

To understand the prevalence of $E$. coli O157:H7, rectal swabs were collected from 15 different organized and unorganized farms and streaked onto the SMAC; the non-sorbitol fermenting colonies were selected. During the initial screening, $40.85 \%$ of samples from the cattle and water were presumptive positive. The representative colonies from each presumptive positive sample were further confirmed by multiplex PCR [19]. O157, H7, and $V T$ were confirmed in 2/105 (1.90\%), 29/105 (27.61\%), and $41 / 105(39.04 \%)$ of samples, respectively. The data reveal the presence of O157 and VTEC strains in the healthy cattle from Pune. The frequent isolation of E. coli $\mathrm{O} 157: \mathrm{H} 7$ from healthy cattle is a serious public health concern. A similar study to understand the prevalence of O157:H7 in cattle by Leung et al., [26] in Hong Kong reported 409/986 (41.5\%) and 9/409 (2.20\%) samples positive for VTEC and O157:H7. Similar observations were made by Leung et al., [26]; wherein, O157:H7 was detected in 17/1226 (1.34\%) of the samples analyzed.

In the present study, the PCR confirmed VTEC exhibited cytotoxicity on Vero cells. The occurrence of VTEC in healthy cattle in Pune is of serious health concern. In a previous report, the presence of cytotoxic VTEC in the healthy population of cattle from West Bengal has been reported by Khan et al., [21].

All E. coli isolates obtained were resistant to at least one or more antimicrobial agents used in this study. Resistance toward penicillin G, piperacillin, tetracycline, cotrimoxazole, ampicillin, and nitrofurantoin was observed. A similar pattern of antimicrobial resistance in $E$. coli isolates from cattle has been reported in other studies $[12,27,28]$. High occurrence of antimicrobial resistance in E. coli $\mathrm{O} 157$ isolates from cattle may confer a selective advantage toward intestinal colonization. Furthermore, this further leads to increased fecal shedding of antimicrobial-resistant E. coli $\mathrm{O} 157: \mathrm{H} 7$. Although a recent study on meta-analysis showed no association between the use of antibiotics and the incidence of HUS, the use of antibiotics for the treatment is unclear and more strain-specific trails are recommended [29]. 


\section{Conclusion}

Our findings suggest that dairy cattle are a frequent reservoir of E. coli serotype O157:H7 and another Shiga toxin E. coli. The VTEC isolates were resistant to the most common antimicrobials and harbor genes for cytotoxicity. The findings warrant additional screening studies of VTEC in both the organized and unorganized cattle farming sector in India to understand the prevalence and characterization of virulence attributes.

\section{Authors' Contributions}

SSK designed the experiments and supervised the study. DBS and SS collected the samples, performed experiments, and analyzed the results. DBS and SSK prepared the draft manuscript. SDS helped in critical review and data representation of the manuscript. All authors approved this manuscript for publication. All authors read and approved the final manuscript.

\section{Acknowledgments}

The authors would like to thank Symbiosis School of Biological Sciences, Symbiosis International (Deemed University), India, for providing research funds to conduct the present study. The authors are thankful to Dr. Shamim Shiekh, Dr. Jyoti Mane, and Dr. Deepa Kothule (Livestock Development Officer) Animal Husbandry Department, Government of Maharashtra, India, for helping in samples collection.

\section{Competing Interests} interests.

The authors declare that they have no competing

\section{Publisher's Note}

Veterinary World remains neutral with regard to jurisdictional claims in published institutional affiliation.

\section{References}

1. Singh, P., Bist, B., Sharma, B. and Yadav, A.K. (2017) A study on prevalence and virulence determinants of verotoxic E. coli (VTEC) isolated from Yamuna river water around the Mathura region of India. Environ. Ecol., 35(3): 2021-2025.

2. Parul, S., Bist, B., Sharma, B., Jain, U. and Yadav, J.K. (2016) A study on association of virulence determinants of verotoxic Escherichia coli isolated from cattle calves. Vet. World, 9(8): 915.

3. Asime, L.J., Egbe, J.G. and Cecilia, E. (2020) Isolation of Escherichia coli 0157: H7 from selected food samples sold in local markets in Nigeria. Afr. J. Food Sci., 14(2): 32-37.

4. Rangel, J.M., Sparling, P.H., Crowe, C., Griffin, P.M. and Swerdlow, D.L. (2005) Epidemiology of Escherichia coli O157:H7 outbreaks, United States, 1982-2002. Emerg. Infect. Dis., 11(4): 603-609.

5. Heiman, K.E., Mody, R.K., Johnson, S.D., Griffin, P.M. and Gould, L.H. (2015) Escherichia coli O157 outbreaks in the United States, 2003-2012. Emerg. Infect. Dis., 21(8): 1293-1301.

6. Currie, A., Honish, L., Cutler, J., Locas, A., Lavoie, M., Gaulin, C., Galanis, E., Tschetter, L., Chui, L., Taylor, M., Jamieson, F., Gilmour, M., Ng, C., Mutti, S., Mah, V.,
Hamel, M., Martinez, A., Buenaventura, E., Hoang, L., Pacagnella, A., Ramsay, D., Bekal, S., Coetzee, K., Berry, C. and Farber, J. (2019) Outbreak of Escherichia coli O157:H7 infections linked to mechanically tenderized beef and the largest beef recall in Canada, 2012. J. Food Prot., 82(9): 1532-1538

7. Stein, R.A. and Katz, D.E. (2017) Escherichia coli, cattle and the propagation of disease. FEMS Microbiol. Lett., 364(6): fnx050.

8. Shayegh, J. (2017) Prevalence of Escherichia coli O157:H7 in bovine feces in North West of Iran. Microbiol. Res., 8(1): 6587.

9. Mishra, R.P., Jain, U., Bist, B., Verma, A.K. and Kumar, A. (2016) Prevalence of vero toxic Escherichia coli in fecal samples of domestic as well as wild ruminants in Mathura districts and Kanpur zoo. Vet. World., 9(1): 71.

10. Menge, C. (2020) Molecular biology of Escherichia coli Shiga toxins' effects on mammalian cells. Toxins, 12(5): 345 .

11. Khan, A., Das, S.C., Ramamurthy, T., Sikdar, A., Khanam, J., Yamasaki, S. and Nair, G.B. (2002a) Antibiotic resistance, virulence gene, and molecular profiles of Shiga toxin-producing Escherichia coli isolates from diverse sources in Calcutta, India. J. Clin. Microbiol., 40(6): 2009-15.

12. Manna, S.K., Brahmane, M., Manna, C., Batabyal, K. and Das, R. (2006) Occurrence, virulence characteristics and antimicrobial resistance of Escherichia coli $\mathrm{O} 157$ in slaughtered cattle and diarrhoeic calves in West Bengal, India. Lett. Appl. Microbiol., 43(4): 4050409.

13. Hazarika, R.A., Singh, D.K., Kapoor, K.N., Bhilegaonkar, K., Agarwal, R.K. and Malik, S.V.S. (2003) Survivability of vero toxic Escherichia coli O111 against sodium benzoate and potassium sorbate added to simulating media for beef gravy. J. Vet. Public Health., 1: 103-112.

14. Bessalah, S., Fairbrother, J.M., Salhi, I., Vanier, G., Khorchani, T., Seddik, M.M. and Hammadi, M. (2020) Characterization and antimicrobial susceptibility of Escherichia coli isolated from healthy farm animals in Tunisia. Anim. Biotechnol.,p.1-10.

15. To, C. and Bhunia, A.K. (2019) Three-dimensional vero cell-platform for rapid and sensitive screening of Shiga-toxin producing Escherichia coli. Front. Microbiol., 10: 949.

16. Blanco, J.E., Blanco, M., Alonso, M.P., Mora, A., Dahbi, G., Coira, M.A. and Blanco, J. (2004) Serotypes, virulence genes, and intimin types of Shiga toxin (verotoxin)-producing Escherichia coli isolates from human patients: Prevalence in Lugo, Spain, from 1992 through 1999. J. Clin. Microbiol., 42(1): 311-319.

17. Prakasan, S., Prabhakar, P., Lekshmi, M., Kumar, S. and Nayak, B.B. (2018) Isolation of Shiga toxin-producing Escherichia coli harboring variant Shiga toxin genes from seafood. Vet. World., 11(3): 379.

18. Franco, A., Lovari, S., Cordaro, G., Di Matteo, P., Sorbara, L., Iurescia, M. and Battisti, A. (2009) Prevalence and concentration of verotoxigenic Escherichia coli O157:H7 in adult sheep at slaughter from Italy. Zoonoses Public Health, 56(5): 215-220.

19. Nagano, I., Kunishima, M., Itoh, Y., Wu, Z. and Takahashi, Y. (1998) Detection of verotoxin-producing Escherichia coli O157: $\mathrm{H} 7$ by multiplex polymerase chain reaction. Microbiol. Immunol., 42(5): 371-376.

20. Ammerman, N.C., Beier-Sexton, M. and Azad, A.F. (2008) Growth and maintenance of vero cell lines. Curr. Protoc. Microbiol., 11(1): A-4E.

21. Khan, A., Yamasaki, S., Sato, T., Ramamurthy, T., Pal, A., Datta, S., Chowdhury, N.R., Das, S.C., Sikdar, A., Tsukamoto, T., Bhattacharya, S.K., Takeda, Y. and Nair, G.B. (2002b) Prevalence and genetic profiling of virulence determinants of non-O157 Shiga toxin-producing Escherichia coli isolated from cattle, beef, and humans, Calcutta, India. Emerg. Infect. Dis., 8(1): 54-62.

22. Elbagoury, A.M., Shawish, R.R. and Edris, A.M. (2016) Prevalence and molecular characterization of Shiga 
toxin-producing E. coli isolated from some locally produced beef products. J. Adv. Res. Med. Health Sci., 2(5): 17-29.

23. Bruballa, A.C., Shiromizu, C.M., Bernal, A.M., Pineda, G.E., Sabbione, F., Trevani, A.S. and Palermo, M.S. (2020) Role of Shiga toxins in cytotoxicity and immunomodulatory effects of Escherichia coli O157: H7 during host-bacterial interactions in vitro. Toxins, 12(1): 48.

24. Abreham, S., Teklu, A., Cox, E. and Tessema, T.S. (2019) Escherichia coli O157: H7: Distribution, molecular characterization, antimicrobial resistance patterns and source of contamination of sheep and goat carcasses at an export abattoir, Mojdo, Ethiopia. BMC Microbiol., 19(1): 215.

25. Adamu, M.T., Shamsul, B.M.T., Desa, M.N. and KhairaniBejo, S. (2014) A review on Escherichia coli O157: H7-the super pathogen. Health, 5(2): 118-134.
26. Leung, P.H.M., Yam, W.C., Ng W.W.S. and Peiris, J.S.M. (2001) The prevalence and characterization of verotoxin-producing Escherichia coli isolated from cattle and pigs in an abattoir in Hong Kong. Epidemiol. Infect., 126(2): 173-179.

27. Ratnam, S., March, S.B., Ahmed, R., Bezanson, G.S. and Kasatiya, S. (1988) Characterization of Escherichia coli serotype O157: H7. J. Clin. Microbiol., 26(10): 2006-2012.

28. Mahmoud, A.S., Mittal, D., Filia, G., Ramneek, V. and Mahajan, V. (2020) Prevalence of antimicrobial resistance patterns of Escherichia coli faecal isolates of cattle. Int. J. Curr. Microbiol. App. Sci., 9(3): 1850-1859.

29. Harkins, V.J., McAllister, D.A. and Reynolds, B.C. (2020) Shiga-toxin E. coli hemolytic uremic syndrome: Review of management and long-term outcome. Curr. Pediatr. Rep., 8(1): 16-25.

$* * * * * * * *$ 